\title{
Avaliação do conhecimento sobre hemoterapia e segurança transfusional de profissionais de Enfermagem
}

\author{
Evaluation of knowledge about hemotherapy and transfusional care of nurses
}

Oranice Ferreira ${ }^{1}$

Edson Z. Martinez ${ }^{2}$

Celso A. Mota ${ }^{3}$

Antônio M. Silva ${ }^{1}$

\begin{abstract}
Os riscos envolvidos na transfusão de sangue e hemoderivados podem ser conseqüentes de procedimentos inadequados, erros ou omissões dos profissionais responsáveis pela transfusão. O presente estudo objetivou determinar o nível de conhecimento sobre o assunto e a adequação das práticas transfusionais dos profissionais de Enfermagem que atuam em um grande hospital universitário do interior de São Paulo. O estudo foi realizado durante um treinamento teórico em Hemoterapia, onde foi aplicado um instrumento de coleta de dados antes e após o treinamento, caracterizando estes profissionais e avaliando seus conhecimentos sobre o tema. Participaram enfermeiros, auxiliares e técnicos de enfermagem responsáveis pela administração de transfusões. Mais da metade se sente pouco ou mal informada sobre o assunto. Grande parte referiu que os pacientes não são orientados sobre sinais e sintomas de reações transfusionais, ainda referindo procedimentos incorretos para aquecimento do sangue. A avaliação de conhecimentos evidenciou lacunas importantes na capacitação destes profissionais. Rev. bras. hematol. hemoter. 2007;29(2):160-167.
\end{abstract}

Palavras-chave: Conhecimento; capacitação em serviço; hemoterapia; transfusão de sangue.

\section{Introdução}

Ainda que os novos desenvolvimentos de tratamentos de saúde venham apresentando expressivos progressos, não se encontrou como substituir o sangue humano para fins terapêuticos. A transfusão de sangue tem sido sempre muito importante como suporte na realização de muitos tratamentos, como os transplantes, quimioterapias e diversas cirurgias. A medicina transfusional é um complexo processo dependente de vários profissionais. Para realizá-lo com segurança, cada profissional depende não só de seus próprios conhecimentos e habilidades, mas também dos conhecimentos e habilidades de toda a equipe e da eficiência do sistema. ${ }^{1}$ A Resolução da Diretoria Colegiada (RDC) 153 da Agência Nacional de Vigilância Sanitária (Anvisa), de 14/06/04, que normatiza no Brasil as atividades de hemoterapia, estabelece regras e procedimentos que devem ser conhecidos e seguidos pelos profissionais que trabalham com transfusões, bem como o padrão de documentação relacionada a estes procedimentos. $^{2}$

A transfusão de hemocomponentes e hemoderivados, no entanto, não está livre de riscos. Complicações relacionadas à transfusão podem ocorrer, e algumas delas podem trazer sérios prejuízos aos pacientes, inclusive fatais. Entre as chamadas reações transfusionais estão as hemolíticas agudas, as anafiláticas, as febris não hemolíticas, as complicações pulmonares, o desequilíbrio eletrolítico, as sepsis bacterianas, a hipotermia, a doença do enxerto versus hospedeiro, a aloimunização, a sobrecarga de volume, a sobrecarga de ferro e a imunossupressão. ${ }^{3}$ Vários fatores podem contribuir para aumentar as chances do paciente experimentar uma complicação relacionada à transfusão. Isto inclui o tipo de

${ }^{1}$ Hemocentro - Centro Regional de Hemoterapia do Hospital das Clínicas da Faculdade de Medicina de Ribeirão Preto, Universidade de São Paulo, HCFRMP-USP.

${ }^{2}$ Departamento de Medicina Social, Faculdade de Medicina de Ribeirão Preto, Universidade de São Paulo (FMRP-USP).

${ }^{3}$ Departamento de Enfermagem do Centro Universitário Barão de Mauá, Ribeirão Preto.

Correspondência: Edson Zangiacomi Martinez

Departamento de Medicina Social - Faculdade de Medicina de Ribeirão Preto - USP

Av. Bandeirantes 3900

14049-900 - Ribeirão Preto-SP - Brasil

E-mail:edson@fmrp.usp.br 
componente que está sendo transfundido, as características do paciente e suas condições médicas, o uso de equipamentos inadequados, as soluções endovenosas incompatíveis, os procedimentos inadequados e erros ou omissões por parte da equipe que presta cuidados aos pacientes. ${ }^{1}$ Embora algumas reações sejam inevitáveis, a maioria das reações transfusionais fatais é atribuída a erro humano. ${ }^{1}$

Uma das mais importantes causas de morte associadas à transfusão é a reação transfusional hemolítica aguda. A causa mais comum deste tipo de reação é a transfusão de sangue ABO incompatível. Embora erros atribuídos aos bancos de sangue e laboratórios possam causar este tipo de reação, a grande maioria é causada por falhas no momento da instalação do hemocomponente, devido à checagem inadequada dos dados de identificação. ${ }^{1,3}$ Centros cirúrgicos movimentados e salas de emergência podem ser especialmente vulneráveis a erros devido à natureza emergencial das transfusões.

Embora eliminar totalmente a possibilidade de erro humano seja impossível, reduzir as oportunidades para que eles ocorram pode ser um objetivo facilmente alcançável. A segurança na administração do sangue depende de indivíduos realizando um trabalho completo e competente. Ter procedimentos escritos, adequados e disponíveis para providenciar à equipe instruções adequadas e consistentes de como proceder nos cuidados do paciente receptor de transfusão certamente contribui para aumentar a segurança transfusional. Para que estes procedimentos sejam efetivos, eles devem indicar claramente o que deve ser feito e a equipe deve ser treinada adequadamente para usá-los. ${ }^{1}$

Os profissionais de Enfermagem exercem um papel fundamental na segurança transfusional. Eles não apenas administram transfusões, mas também devem conhecer as suas indicações, providenciar a checagem de dados importantes na prevenção de erros, orientar os pacientes sobre a transfusão, detectar, comunicar e atuar no atendimento das reações transfusionais e documentar todo o processo. ${ }^{1}$ A atuação destes profissionais pode minimizar significativamente os riscos do paciente que recebe transfusão e evitar danos, se o gerenciamento do processo transfusional ocorrer com a eficiência necessária. Por outro lado, profissionais sem conhecimentos em hemoterapia e sem habilidades suficientes podem causar complicações e danos importantes. No Brasil, as competências e atribuições do enfermeiro em hemoterapia são regulamentadas conforme a resolução número 306/2006, do Conselho Federal de Enfermagem (Confe). Segundo esta resolução, o enfermeiro deve planejar, executar, coordenar, supervisionar e avaliar os procedimentos de hemoterapia nas unidades de saúde, visando assegurar a qualidade do sangue, hemocomponentes e hemoderivados. ${ }^{4}$

Para sua melhor eficiência, os profissionais de enfermagem devem atuar em ambientes que reconheçam a importância de reduzir erros e aumentar a segurança através de uma abordagem não punitiva, que se preocupe em analisar de perto os erros e enganos cometidos mesmo que pareçam pequenos. ${ }^{5}$ Um artigo ${ }^{6}$ sobre negligência criminal e erro de medicação relatou o caso de três enfermeiras que foram indiciadas criminalmente, em 1996, por um erro que causou a morte de um recém-nascido. A análise do caso revelou que mais de cinqüenta falhas ocorreram no sistema, contribuindo para que o erro acontecesse. Na opinião dos autores, se uma destas falhas não tivesse acontecido, o erro poderia ter sido evitado ou teria sido detectado antes de causar danos ao paciente. Uma equipe com níveis adequados de conhecimento é essencial para um sistema seguro, sendo de fundamental importância assegurar mecanismos para monitorar este conhecimento. Uma pesquisa realizada entre grupos de médicos e enfermeiras sobre os seus conhecimentos relacionados à transfusão ${ }^{4}$ relatou que ambos os grupos receberam em suas avaliações notas significativamente mais baixas que as esperadas. Após um processo educacional, a pesquisa foi repetida, demonstrando um incremento significante de conhecimentos sobre o assunto. Isto demonstra a importância de atualização constante de informações e feedback para todos os profissionais envolvidos no processo transfusional.

Uma pesquisa realizada em Aquitaine, França, identificou várias deficiências no conhecimento e práticas de enfermeiras, ${ }^{7}$ relacionadas à transfusão, e considerou a freqüência de treinamentos um dos principais fatores associados a esta deficiência. Os autores indicam um programa de educação continuada para aumentar os conhecimentos e promover mudanças de práticas. Consideram também que o sucesso deste programa é dependente de dois fatores. O primeiro fator é associado à motivação e ao desejo de mudança dos participantes e o segundo dá ênfase ao treinamento dirigido às necessidades dos profissionais e integrado ao ambiente de trabalho.

Em outro estudo realizado com cem enfermeiras na Turquia, ${ }^{3}$ foi encontrada uma alta associação entre as avaliações do conhecimento teórico destas enfermeiras e suas avaliações práticas, evidenciando que o nível de conhecimento teórico afeta positivamente a atuação prática em relação à transfusão de sangue. Os autores observaram também que enfermeiras com menos de seis anos de experiência alcançaram melhores notas nas avaliações teóricas que as com mais de seis anos, e justificaram este achado com o fato de que as mais experientes nunca tinham recebido treinamento em serviço e as menos experientes ainda se lembravam das orientações recebidas na escola. A pesquisa mostrou ainda que um número muito pequeno de enfermeiras realizava procedimentos considerados muito importantes no processo de transfusão ou os executava de forma inadequada, como orientar os pacientes, checar dados de identificação, iniciar lentamente a transfusão, usar métodos adequados de aquecimento do sangue, conhecer e monitorar o paciente quanto aos sinais e sintomas de reações transfusionais e, finalmente, realizar os registros necessários do processo transfusional. Os autores 
concluíram que, na Turquia, as enfermeiras têm um conhecimento limitado sobre transfusão de sangue e não colocam os seus poucos conhecimentos em prática, comprometendo a qualidade dos cuidados do paciente e podendo resultar em sérias complicações.

No Brasil, os hospitais universitários são geralmente formados por clínicas de diversas especialidades e prestam atendimento de saúde de nível terciário. Isto inclui a utilização freqüente de tratamentos onde são necessárias transfusões de sangue. O objetivo do presente estudo é determinar o nível de conhecimentos sobre transfusão e adequação das práticas transfusionais dos profissionais de enfermagem envolvidos com estas, através de um instrumento concebido para este propósito.

\section{Pacientes e Métodos}

O estudo foi realizado em um grande hospital universitário do interior de São Paulo, como parte de um programa de treinamento teórico em hemoterapia proposto aos profissionais de enfermagem (enfermeiros, auxiliares e técnicos de enfermagem) que atuam nas clínicas de diversas especialidades de duas grandes unidades desta instituição.

O treinamento foi ministrado em 15 sessões durante um período de mais ou menos seis meses. Para cada sessão havia uma platéia diferente formada por, no máximo, quarenta profissionais provenientes das diversas clínicas e designados pela Divisão de Enfermagem do hospital em questão. A responsabilidade pela elaboração e administração das aulas, bem como a aplicação dos instrumentos de avaliação, foi de um grupo de enfermeiros e médicos do Centro Regional de Hemoterapia (Hemocentro) ligado a este hospital.

Todos os participantes do treinamento foram orientados e convidados a participar voluntariamente do estudo. Os que aceitaram assinaram o Termo de Consentimento Livre e Esclarecido. Assegurou-se aos profissionais que não quiseram participar que eles não teriam nenhum prejuízo no que se refere ao treinamento. O projeto do estudo e seu respectivo Termo de Consentimento Livre e Esclarecido foram analisados e aprovados pelo Comitê de Ética em Pesquisa do Hospital das Clínicas da Faculdade de Medicina de Ribeirão Preto, Universidade de São Paulo, segundo processo HCRP número 12480/2004.

As aulas tinham duração de quatro horas e foram abordados os seguintes temas: Legislação Vigente em Hemoterapia, Métodos de Obtenção do Sangue e Hemocomponentes, Arsenal Hemoterápico, Cuidados Peritransfusionais e Reações Adversas à Transfusão. Aos participantes do estudo foram aplicados dois instrumentos, um pré e outro póstreinamento. $\mathrm{O}$ instrumento pré-treinamento era composto de duas partes, uma cujo objetivo era caracterizar os profissionais e outra que consistia de um teste de avaliação de seus conhecimentos. O instrumento aplicado pós-treinamento foi o mesmo teste de avaliação de conhecimentos utilizado na fase anterior. O instrumento destinado à caracterização profissional se propunha a colher dados como sexo, idade, escolaridade, formação e experiência profissional, local de trabalho, treinamentos sobre hemoterapia recebidos, autopercepção e outros dados sobre as rotinas relacionadas à transfusão realizadas nos locais onde cada participante vinha exercendo suas funções.

O instrumento destinado à avaliação de conhecimentos era composto por 14 questões, sendo a primeira dividida em três ítens e a $11^{\text {a }}$ composta por dez afirmações para as quais deveriam ser registrados "V" para verdadeiro e "F" para falso, de acordo com a opinião do avaliado. A primeira questão do instrumento referiu-se a conhecimentos sobre as amostras pré-transfusionais, quanto à sua validade, identificação e ao local de identificação. As questões 4, 6 e 7 basearam-se em conhecimentos sobre cuidados pré-transfusionais, como a verificação dos sinais vitais, procedimentos necessários à instalação de uma transfusão de concentrado de hemácias e o tempo máximo para iniciar a transfusão, a partir do recebimento da bolsa de concentrado de hemácias. Foi atribuído para cada item da primeira questão e para cada uma das outras, exceto para a $11^{\mathrm{a}}$, o valor de 0,5 ponto para cada acerto. À $11^{a}$ questão foi atribuído o valor de 2,5 pontos ( 0,25 para cada item correto). Assim, os participantes poderiam obter notas em uma escala de 0 a 10 em suas avaliações.

\section{Análise dos dados}

A análise de correspondências ${ }^{8}$ é uma técnica estatística que permite explorar as associações entre um conjunto de categorias de variáveis qualitativas. Quando a análise se dá em um contexto multivariado, a técnica se baseia no cruzamento simultâneo de todas as variáveis em questão (o que resulta na chamada matriz de Burt ${ }^{9}$ ) e ganha o nome de análise de correspondências múltipla (ACM). Quando aplicada aos dados do presente estudo, indica quais são as características associadas ao conhecimento do profissional sobre hemoterapia e segurança transfusional em um gráfico cartesiano denominado mapa de correspondências. Na ACM, a variação total dos dados é denominada inércia, sendo esta variação decomposta em cada eixo (ou dimensão) do gráfico. Assim, a inércia associada a cada dimensão indica a proporção da variação total que aquele eixo está explicando. Esta análise foi auxiliada pelo procedimento Proc Corresp do programa de computador SAS ${ }^{10}$ versão 8.

\section{Resultados}

\section{Caracterização da amostra}

A amostra foi constituída por 546 profissionais de enfermagem com idade média de 36,8 anos, sendo 51,8\% composta de auxiliares, 33,5\% de enfermeiros e 14,7\% de técnicos de enfermagem. A Tabela 1 mostra uma descrição desta amostra, onde se observa que $89 \%$ destes profissionais que 
Tabela 1. Descrição da amostra

\begin{tabular}{|c|c|c|c|c|c|c|c|c|}
\hline & \multirow{2}{*}{ Total } & \multirow{2}{*}{$(\%)$} & \multicolumn{2}{|c|}{ Auxiliares } & \multicolumn{2}{|c|}{ Enfermeiros } & \multicolumn{2}{|c|}{ Técnicos } \\
\hline & & & $n$ & (\%) & $n$ & (\%) & $n$ & (\%) \\
\hline \multicolumn{9}{|l|}{ Sexo } \\
\hline Masculino & 62 & (11) & 41 & (15) & 8 & (4) & 13 & (16) \\
\hline Feminino & 484 & (89) & 242 & (85) & 175 & (96) & 67 & (84) \\
\hline \multicolumn{9}{|l|}{ Idade } \\
\hline$<25$ anos & 174 & (32) & 73 & (26) & 75 & (41) & 26 & (33) \\
\hline 25 a 30 anos & 180 & (33) & 91 & (32) & 60 & (33) & 29 & (36) \\
\hline 31 a 40 anos & 148 & (27) & 92 & (32) & 40 & (22) & 16 & (20) \\
\hline Mais de 40 & 44 & (8) & 27 & (10) & 8 & (4) & 9 & (11) \\
\hline \multicolumn{9}{|l|}{ Escolaridade } \\
\hline $1^{\circ}$ grau completo & 65 & (12) & 65 & (23) & - & & - & \\
\hline $2^{\circ}$ grau completo & 279 & (51) & 204 & (72) & - & & 74 & (92) \\
\hline Superior & 170 & (31) & 12 & (4) & 153 & (84) & 6 & (8) \\
\hline Pós-graduação & 32 & (6) & 2 & (1) & 30 & $(16)$ & - & \\
\hline \multicolumn{9}{|c|}{ Tempo de experiência na função } \\
\hline Menos de 1 ano & 38 & (7) & 15 & (5) & 20 & $(11)$ & 3 & (4) \\
\hline 1 a 5 anos & 150 & (28) & 70 & $(25)$ & 64 & (35) & 16 & $(20)$ \\
\hline 6 anos ou mais & 355 & $(65)$ & 196 & (70) & 98 & (54) & 61 & (76) \\
\hline Não respondeu & 3 & & 2 & & 1 & & - & \\
\hline \multicolumn{9}{|c|}{ Freqüência em que realiza transfusões } \\
\hline Semanalmente & 278 & (51) & 142 & $(50)$ & 100 & (55) & 36 & $(45)$ \\
\hline No mínimo $1 x$ mês & 172 & (32) & 94 & (33) & 54 & (30) & 24 & $(30)$ \\
\hline$<1 x$ ao mês & 55 & (10) & 24 & (9) & 18 & $(10)$ & 13 & (16) \\
\hline $1 x$ ano ou nunca & 40 & (7) & 23 & (8) & 10 & (5) & 7 & (9) \\
\hline Não respondeu & 1 & & - & & 1 & & - & \\
\hline \multicolumn{9}{|c|}{ Recebeu orientações ou treinamento } \\
\hline Sim & 374 & $(69)$ & 166 & (59) & 144 & (79) & 64 & $(80)$ \\
\hline Não & 170 & (31) & 116 & $(41)$ & 38 & $(21)$ & 16 & $(20)$ \\
\hline Não respondeu & 2 & & 1 & & 1 & & - & \\
\hline Total & 546 & $(100)$ & 283 & (100) & 183 & (100) & 80 & (100) \\
\hline
\end{tabular}

obstétrico ou clínica obstétrica. Os demais profissionais trabalham em locais como clínica cirúrgica, unidade especializada em tratamento de doenças infecciosas, clínica ortopédica, unidade de transplante renal, serviço de urgência/emergência e unidade de queimados. Vários destes locais de trabalho destacam-se pelo atendimento de pacientes cujo tratamento inclui a necessidade de transfusão de sangue.

\section{Conhecimentos sobre transfusão}

Os participantes foram questionados quanto aos seus sentimentos sobre os conhecimentos que possuíam a respeito de transfusão. Observou-se que, dentre os 546 participantes, $321(58,8 \%)$ referiram sentir-se pouco ou mal informados sobre o assunto (Tabela 2). Destes, 77,6\% administram transfusão com grande freqüência, ou seja, no mínimo uma vez por mês. Observou-se, também, que um percentual muito pequeno $(2,2 \%)$ referiu sentir-se muito bem informado sobre o assunto. A Figura 1 mostra o mapa de correspondências gerado da análise dos dados da Tabela 2, onde se verifica que as respostas "mal informado", "pouco informado", "informado" e "muito bem informado" são representadas nesta ordem quando projetadas na dimensão 1. Cada categoria das variáveis apresentadas na Tabela 2 é representada no mapa de correspondências pelo seu respectivo rótulo, conforme o rodapé da Figura 1. A nota da primeira prova, categorizada segundo seus quartis, também consta desta análise. Assim, as categorias mais associadas ao sentimento de estar muito bem informado são: possuir curso superior (E3) ou pós-graduação (E4), ser enfermeiro (ENF), tempo de experiência inferior a um ano (T1) e ter obtido uma nota superior a 7,7 na primeira avaliação (Q4). As categorias associadas à resposta "mal informado" são: $1^{\circ}$ grau participaram do estudo eram do sexo feminino. Quanto à freqüência em que administram transfusões, 51\% dos participantes referiram fazê-las semanalmente e 32\%, no mínimo uma vez ao mês. Quando se avalia esta freqüência em relação às categorias profissionais, quase não se observam diferenças principalmente entre auxiliares de enfermagem e enfermeiros, sendo discretamente menor para os técnicos de enfermagem. Em relação ao preparo para realizar esta atividade, $69 \%$ dos profissionais em questão referiram ter recebido algum tipo de treinamento ou orientação. A categoria cujo maior número de profissionais fez referências a treinamento foi a de técnicos de enfermagem (80\%) seguida dos enfermeiros (79\%) e de auxiliares de enfermagem (59\%).

Sobre a distribuição dos profissionais participantes do estudo em relação às especialidades de seu local de trabalho, 110 (20,1\%) exercem atividades em clínica médica, 88 (16,1\%) em centro de terapia intensiva (CTI) neonatal, CTI pediátrica e pediatria, $75(13,7 \%)$ em centro cirúrgico ou de recuperação anestésica, 50 (9,3\%) em CTI adulto e 42 (7,8\%) em centro completo (E1), não haver recebido orientações ou treinamento (RT2) e baixa freqüência de transfusões (uma vez ao ano ou nunca, F4).

Quando questionados sobre orientações ao paciente, antes da transfusão, na clínica onde trabalham, observou-se que $81 \%$ dos profissionais de enfermagem responderam que os pacientes são orientados sobre os benefícios da transfusão. Por outro lado, apenas $40 \%$ responderam que os pacientes são orientados sobre os riscos da transfusão e $60 \%$ sobre sinais e sintomas de reações transfusionais.

Ao serem questionados sobre o aquecimento de hemocomponentes antes da transfusão na clínica onde trabalham, 33\% responderam que é comum surgirem situações onde é indicado este procedimento. A Tabela 3 descreve os métodos utilizados para isto citados pelos participantes do estudo.

Resultados do teste de avaliação de conhecimentos A Tabela 4 mostra o desempenho obtido pelas três ca- 


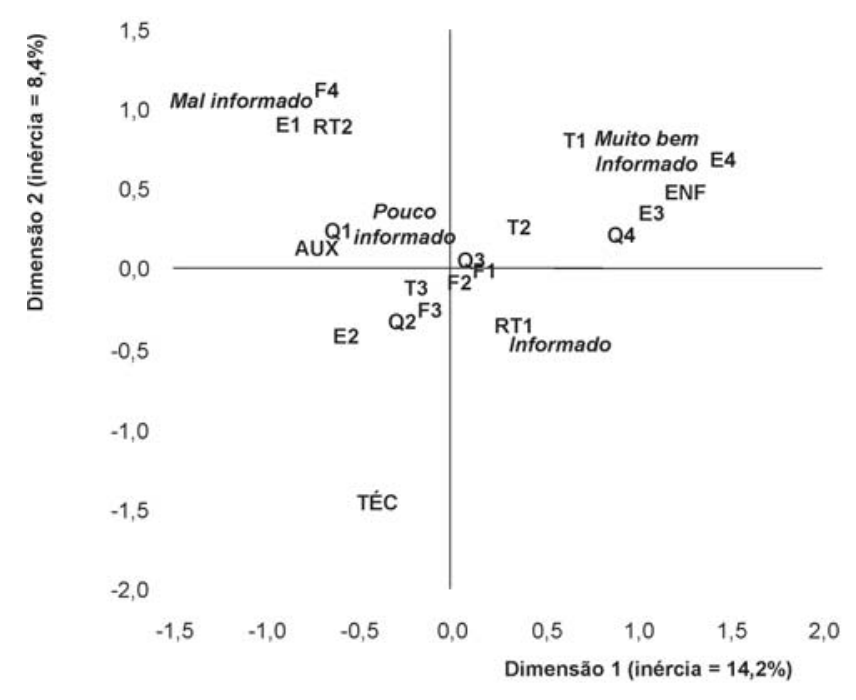

\begin{tabular}{l|c}
\hline Categoria profissional & Freqüência em que realiza transfusões \\
AUX - Auxiliar de Enfermagem & F1 - Semanalmente \\
ENF - Enfermeiro & F2 - No mínimo 1x mês \\
TÉC - Técnico em Enfermagem & F3 - <1x ao mês \\
& F4 - 1x ano ou nunca \\
Escolaridade & Nota na primeira prova \\
E1 - $1^{\circ}$ grau completo & Q2 - menor ou igual a 5,5 \\
E2 - $2^{\circ}$ grau completo & ou igual a 6,25 \\
E3 - Superior & Q3 - acima de 6,25 e \\
E4 - Pós graduação & menor ou igual a 7,7 \\
& Q4 - maior que 7,7 \\
Tempo de experiência na função & Recebeu orientações ou treinamento \\
T1 - Menos de 1 ano & RT1 - Sim \\
T2 - 1 a 5 anos & RT2 - Não \\
T3 - 6 anos ou mais & \\
\hline
\end{tabular}

Figura 1. Visualização das associações entre algumas características dos participantes da pesquisa e a autopercepção do conhecimento sobre transfusão de sangue, por intermédio do mapa gerado pelas duas primeiras dimensões da análise de correspondências múltipla.

tegorias profissionais nos testes de avaliação de conhecimentos. Os auxiliares de enfermagem obtiveram notas entre 2,5 e 8,5 (com mediana 6,0, ou seja, metade dos 283 auxiliares obteve notas iguais ou inferiores a 6,0; e intervalo interquartil 5,25 a 6,75 , ou seja, $25 \%$ ou um quarto dos auxiliares obteve notas iguais ou inferiores a 5,25 enquanto esta mesma proporção, 25\%, obteve notas iguais ou superiores a 6,75); os enfermeiros obtiveram notas entre 3,5 e 10,0 (mediana 6,75, intervalo interquartil 6,0 a 7,5); e os técnicos, notas entre 3,5 e 9,0 (mediana 6,0, intervalo interquartil 5,5 a 6,75) na avaliação pré-treinamento. Na avaliação pós-treinamento, os auxiliares de enfermagem obtiveram notas entre 5,0 e 10,0 (mediana 8,5, intervalo interquartil 8,0 a 9,25); os enfermeiros obtiveram notas entre 5,5 e 10,0 (mediana 9,25, intervalo interquartil 8,5 a 9,5); e os técnicos, notas entre 6,0 e 10,0 (mediana 8,75, intervalo interquartil 8,25 a 9,25). A Tabela 4 mostra as medianas e os terceiros quartis (percentil 75\%) para as notas das avaliações pré e pós- treinamento, segundo algumas características dos profissionais. Estas informações são descritas nesta Tabela em medianas, e não em médias, dado que foram observados em algumas categorias das variáveis associadas a tais características dos profissionais valores médios inflacionados ou deflacionados por algumas notas muito abaixo ou muito acima das demais. A mediana, sendo uma medida robusta a valores extremos, descreveu com maior fidelidade os resultados encontrados. Não foram observadas diferenças no desempenho em relação ao sexo, idade, escolaridade, tempo de experiência e freqüência com que realizam transfusões. Quando se relaciona desempenho no teste pré-treinamento e autopercepção sobre os conhecimentos em relação à transfusão, apenas entre os enfermeiros observa-se uma certa coerência nos resultados, ou seja, melhor desempenho quanto melhor informado se sente o profissional.

Na avaliação pré-treinamento, os ítens para os quais os participantes demonstraram menos conhecimentos através de um menor percentual de acerto foram: composição dos hemocomponentes (24,4\%), local correto para identificação das amostras pré-transfusionais (27,7\%), compatibilidade sangüínea $A B O$ e, quanto ao fator Rh (28,6\%), conservação adequada dos concentrados de plaquetas (27,5\%), limite de tempo permitido para instalação de transfusão de concentrado de hemácias após retirá-lo das condições ideais de conservação (31,9\%), sinais e sintomas de reações transfusionais (33,5\%) e cuidados necessários na transfusão de concentrados de granulócitos (35,3\%).

Os ítens para os quais o grupo demonstrou mais conhecimentos foram: a necessidade da etiqueta de identificação permanecer afixada à bolsa de hemocomponente durante toda a transfusão e ser anexada ao prontuário do paciente após o seu término (98,5\%), a necessidade de haver um pedido formal e assinado pelo médico para realização de transfusões $(98,4 \%)$ e a necessidade de checagem rigorosa dos dados de identificação da bolsa e do paciente antes da instalação da transfusão (98,2\%).

Analisando-se individualmente os ítens avaliados observa-se que as três categorias profissionais tiveram um desempenho semelhante. Os enfermeiros apresentaram um percentual de acerto um pouco maior nos seguintes ítens: validade das amostras pré-transfusionais, cuidados para prevenção de hemólise e conhecimentos sobre indicação e cuidados na administração de fatores de coagulação liofilizados.

No geral, o desempenho pós-treinamento foi satisfatório e semelhante para as três categorias de profissionais (Tabela 4). No entanto, dois ítens se destacaram devido aos profissionais terem conseguido um incremento pequeno no percentual de acertos quando se comparam os testes pré e pós-treinamento: conhecimentos sobre compatibilidade sangüínea $\mathrm{ABO}$ e Rh e cuidados na administração de concentrados de granulócitos. 
Tabela 2. Autopercepção dos profissionais de enfermagem sobre seus conhecimentos a respeito de transfusão de sangue, segundo a escolaridade, tempo de experiência na função, freqüência com que realizam este procedimento, orientações e formação

\begin{tabular}{|c|c|c|c|c|c|c|c|c|}
\hline & \multicolumn{8}{|c|}{ Autopercepção do conhecimento sobre transfusão de sangue } \\
\hline & \multicolumn{2}{|c|}{ Mal informado } & \multicolumn{2}{|c|}{$\begin{array}{c}\text { Pouco } \\
\text { informado }\end{array}$} & \multicolumn{2}{|c|}{ Informado } & \multicolumn{2}{|c|}{$\begin{array}{l}\text { Muito bem } \\
\text { informado }\end{array}$} \\
\hline & Total & $(\%)$ & $\mathrm{n}$ & $(\%)$ & $\mathrm{n}$ & (\%) & $\mathrm{n}$ & $(\%)$ \\
\hline \multicolumn{9}{|l|}{ Escolaridade } \\
\hline $1^{\circ}$ grau completo & 10 & $(26)$ & 35 & (12) & 20 & (9) & 0 & - \\
\hline $2^{\circ}$ grau completo & 23 & (59) & 163 & $(58)$ & 88 & $(42)$ & 4 & (33) \\
\hline Superior & 6 & (15) & 72 & (26) & 86 & $(40)$ & 7 & (59) \\
\hline Pós-graduação & 0 & - & 12 & (4) & 19 & $(9)$ & 1 & (8) \\
\hline \multicolumn{9}{|c|}{ Tempo de experiência na função } \\
\hline Menos de 1 ano & 3 & (8) & 23 & (8) & 10 & (5) & 2 & (17) \\
\hline 1 a 5 anos & 9 & (24) & 78 & (28) & 60 & (28) & 3 & (25) \\
\hline 6 anos ou mais & 26 & (68) & 179 & (64) & 143 & $(67)$ & 7 & (58) \\
\hline \multicolumn{9}{|c|}{ Freqüência em que realiza transfusões } \\
\hline Semanalmente & 21 & $(54)$ & 133 & $(47)$ & 115 & (54) & 9 & (75) \\
\hline No mínimo $1 x$ mês & 6 & (15) & 89 & (32) & 74 & (35) & 3 & (25) \\
\hline$<1 x$ ao mês & 7 & (18) & 31 & (11) & 17 & (8) & 0 & - \\
\hline $1 x$ ano ou nunca & 5 & (13) & 28 & $(10)$ & 7 & (3) & 0 & - \\
\hline \multicolumn{9}{|c|}{ Recebeu orientações ou treinamento } \\
\hline Sim & 9 & $(24)$ & 171 & (61) & 186 & (87) & 8 & (73) \\
\hline Não & 29 & (76) & 111 & (39) & 27 & (13) & 3 & (27) \\
\hline \multicolumn{9}{|l|}{ Formação } \\
\hline Auxiliares & 26 & (67) & 171 & (61) & 83 & (39) & 3 & (25) \\
\hline Enfermeiros & 5 & (13) & 74 & (26) & 96 & (45) & 8 & (67) \\
\hline Técnicos & 8 & (20) & 37 & (13) & 34 & (16) & 1 & (8) \\
\hline
\end{tabular}

Tabela 3. Métodos de aquecimento de hemocomponentes citados pelos respondentes

\begin{tabular}{|c|c|}
\hline Método de aquecimento & $\begin{array}{l}\text { Número de } \\
\text { citações }\end{array}$ \\
\hline Deixar em temperatura ambiente sem controle de tempo & 131 \\
\hline Deixar em temperatura ambiente por até 30 minutos & 34 \\
\hline $\begin{array}{l}\text { Colocar a bolsa sobre equipamentos elétricos ligados } \\
\text { (quentes) }\end{array}$ & 12 \\
\hline Envolver a bolsa em pano e deixar por tempo indeterminado & 7 \\
\hline Misturar SF 0,9\% quente ao hemocomponente & 6 \\
\hline Colocar a bolsa em microondas comum & 6 \\
\hline $\begin{array}{l}\text { Mergulhar a bolsa em água quente ou em banho-maria } \\
\text { comum }\end{array}$ & 5 \\
\hline Colocar a bolsa sob torneira de água quente & 4 \\
\hline Solicitar ao serviço de hemoterapia que aqueça a bolsa & 3 \\
\hline $\begin{array}{l}\text { Utilizar equipamento específico para aquecimento } \\
\text { de hemocomponentes }\end{array}$ & 1 \\
\hline
\end{tabular}

procedimento vinculado a uma ou outra especialidade, podendo ocorrer em quase todas as clínicas, em maior ou menor proporção. Mais de três quartos dos profissionais que executam esta atividade com grande freqüência sentem-se pouco ou mal informados sobre o assunto e isto se agrava para os auxiliares e técnicos de enfermagem, com a ausência de treinamentos e à medida que a transfusão é menos freqüente no local onde trabalham. $\mathrm{O}$ fato de profissionais com mais tempo de experiência sentirem-se menos informados que os menos experientes pode ser um reflexo da ausência de programas de reciclagem, que distancia o profissional dos conhecimentos adquiridos no curso de formação, com o passar dos anos, e deixa-os desatualizados. Este fenômeno já foi descrito em outros trabalhos. ${ }^{3}$

Os dados sobre orientações que são feitas aos pacientes receptores de transfusão mostram que são enfatizados os aspectos referentes aos benefícios da transfusão, pouco se esclarecendo sobre os seus riscos. O fato de $40 \%$ dos participantes terem referido que os pacientes não são orientados sobre os sinais e sintomas de reações transfusionais chama a atenção para um sério problema, uma vez que a detecção precoce de um efeito adverso constitui uma arma poderosa para minimizar os danos ao paciente e que a colaboração do mesmo, referindo qualquer anormalidade sugestiva de reação o mais rápido possível, é de extrema importância. Por outro lado, isto constitui um achado completamente explicável, uma vez que este foi um dos ítens onde os profissionais, na avaliação pré-treinamento, demonstraram ter menos conhecimentos, o que ratifica a crucial importância do preparo destes profissionais para administrar transfusão de sangue.

Outro problema importante que pudemos observar através dos resultados deste estudo é a freqüência com que os participantes referiram observar situações onde o aquecimento de sangue está indicado e os métodos utilizados em tal procedimento. A Resolução da Diretoria Colegiada (RDC) número 153 da Anvisa, no seu item K.4.4, diz que o aquecimento de hemocomponentes deve ser realizado, quando houver indicação, de forma controlada, em aquecedores próprios para este fim e que devem haver protocolos escritos que definam as indicações e os procedimentos para o aquecimento do sangue. Nesta mesma norma, no item K.4.1 existe a orientação de que componentes eritrocitários só podem permanecer à temperatura ambiente por, no máximo, 30 minutos, antes da instalação da transfusão. Na Tabela 3 podemos observar o quanto é comum a prática de deixar a bolsa de hemocomponente à temperatura ambiente, sem nenhum controle de tempo, com o objetivo de evitar instalá-lo gelado. Houve apenas uma única citação de uso de equipamento específico para 
Tabela 4. Desempenho obtido pelas três categorias profissionais nos testes de avaliação de conhecimentos, antes e depois do treinamento, segundo algumas variáveis. As notas dos profissionais são descritas por medianas e, entre parênteses, o terceiro quartil (o percentil 75\%)

\begin{tabular}{|c|c|c|c|c|c|c|}
\hline & \multicolumn{2}{|c|}{ Auxiliares } & \multicolumn{2}{|c|}{ Enfermeiros } & \multicolumn{2}{|c|}{ Técnicos } \\
\hline & antes & depois & antes & depois & antes & depois \\
\hline \multicolumn{7}{|l|}{ Sexo } \\
\hline Masculino & $6,25(7,25)$ & $8,25(9,00)$ & $6,00(7,38)$ & $8,75(9,75)$ & $6,50(6,75)$ & $8,75(9,25)$ \\
\hline Feminino & $6,00(6,75)$ & $8,50(9,25)$ & $6,75(7,50)$ & $9,25(9,50)$ & $6,00(6,50)$ & $8,75(9,25)$ \\
\hline \multicolumn{7}{|l|}{ Idade } \\
\hline$<25$ anos & $6,25(7,00)$ & $8,88(9,25)$ & $7,25(7,75)$ & $9,25(9,50)$ & $6,25(7,00)$ & $9,00(9,25)$ \\
\hline 25 a 30 anos & $6,25(7,00)$ & $8,75(9,25)$ & $6,63(7,50)$ & $9,00(9,50)$ & $6,00(6,50)$ & $8,50(9,25)$ \\
\hline 31 a 40 anos & $6,00(6,50)$ & $8,38(9,00)$ & $6,50(7,00)$ & $8,75(9,50)$ & $6,00(6,38)$ & $8,63(9,13)$ \\
\hline Mais de 40 & $6,25(6,50)$ & $8,25(8,75)$ & $6,25(7,63)$ & $9,25(9,88)$ & $6,00(6,50)$ & $8,75(9,00)$ \\
\hline \multicolumn{7}{|l|}{ Escolaridade } \\
\hline $1^{\circ}$ grau completo & $6,00(6,50)$ & $8,25(9,00)$ & - & & & \\
\hline $2^{\circ}$ grau completo & $6,00(6,88)$ & $8,50(9,25)$ & - & & $6,00(6,75)$ & $8,75(9,25)$ \\
\hline Superior & $6,25(6,50)$ & $9,13(9,38)$ & $6,75(7,50)$ & $9,00(9,50)$ & $6,25(6,50)$ & $8,25(9,00)$ \\
\hline Pós-graduação & $7,25(8,00)$ & $9,13(9,50)$ & $7,50(7,75)$ & $9,25(9,50)$ & - & \\
\hline \multicolumn{7}{|l|}{ Tempo de experiência } \\
\hline Menos de 1 ano & $6,75(7,50)$ & $9,00(9,25)$ & $6,75(7,88)$ & $9,38(9,50)$ & $6,75(7,50)$ & $8,75(8,75)$ \\
\hline 1 a 5 anos & $6,38(7,00)$ & $8,75(9,25)$ & $7,25(7,75)$ & $9,25(9,50)$ & $6,25(6,75)$ & $9,25(9,50)$ \\
\hline 6 anos ou mais & $6,00(6,50)$ & $8,50(9,00)$ & $6,50(7,25)$ & $9,00(9,50)$ & $6,00(6,50)$ & $8,75(9,25)$ \\
\hline \multicolumn{7}{|c|}{ Freqüência em que realiza transfusões } \\
\hline Semanalmente & $6,00(6,75)$ & $8,50(9,00)$ & $7,00(7,88)$ & $9,00(9,50)$ & $6,13(6,75)$ & $8,63(9,25)$ \\
\hline No mínimo 1x mês & $6,25(6,75)$ & $8,50(9,25)$ & $6,75(7,50)$ & $9,25(9,50)$ & $6,13(6,75)$ & $9,00(9,75)$ \\
\hline$<1 x$ ao mês & $6,00(6,63)$ & $8,25(8,88)$ & $6,63(7,25)$ & $9,50(9,50)$ & $5,75(6,25)$ & $8,50(9,25)$ \\
\hline $1 x$ ano ou nunca & $6,25(6,50)$ & $8,75(9,25)$ & $5,75(7,00)$ & $8,88(9,25)$ & $5,50(7,25)$ & $8,75(9,25)$ \\
\hline \multicolumn{7}{|l|}{ Conhecimento } \\
\hline Mal informado & $5,50(6,00)$ & $8,38(9,00)$ & $6,25(6,75)$ & $9,25(9,50)$ & $6,63(7,12)$ & $8,50(9,25)$ \\
\hline Pouco informado & $6,25(6,75)$ & $8,75(9,25)$ & $6,75(7,50)$ & $8,88(9,50)$ & $5,75(6,25)$ & $8,75(9,25)$ \\
\hline Informado & $6,25(7,00)$ & $8,50(9,25)$ & $7,00(7,88)$ & $9,25(9,50)$ & $6,25(6,75)$ & $8,75(9,25)$ \\
\hline Muito bem informado & $4,00(7,25)$ & $7,50(9,25)$ & $7,75(9,25)$ & $9,63(9,75)$ & 8,50 (a) & $9,00 \quad(a)$ \\
\hline Total & $6,00(6,75)$ & $8,50(9,25)$ & $6,75(7,50)$ & $9,25(9,50)$ & $6,00(6,75)$ & $8,75(9,25)$ \\
\hline
\end{tabular}

(a) Não foi calculado o terceiro quartil pois há apenas um indivíduo nestas condições

aquecimento de sangue e várias outras referências a procedimentos completamente contra-indicados que colocam em sério risco a qualidade dos hemocomponentes transfundidos podendo inclusive causar sérios danos aos receptores.

Estes achados também são coerentes com os resultados do teste de avaliação de conhecimentos pré-treinamento, considerando que este foi outro item para o qual os participantes demonstraram ter pouca informação. Em relação aos ítens para os quais o desempenho no teste pós-treinamento ficou aquém do desejado, a explicação pode estar nos seguintes fatos: (a) a transfusão de granulócitos é um procedi- mento bem menos freqüente que os outros tipos de transfusão e muitos dos participantes do estudo nunca tinham tido a oportunidade de acompanhar; (b) o item compatibilidade sangüínea ABO e Rh foi superficialmente abordado durante o treinamento.

\section{Conclusão}

O presente estudo evidencia que os profissionais de Enfermagem que administram transfusões de sangue e hemoderivados nem sempre estão adequadamente preparados para assumir esta responsabilidade e isto pode trazer 
riscos à saúde coletiva. Esta realidade não é diferente daquela observada em outros lugares, inclusive em outros países considerados mais desenvolvidos que o Brasil. O Conselho Europeu, em dezembro de 2004, considerando a importância do assunto, divulgou recomendações para que os governantes dos seus estados-membros tomassem todas as medidas necessárias para assegurar que: (1) todos os enfermeiros recebessem treinamento sobre transfusões de sangue; (2) apenas enfermeiros que tivessem sido treinados e com qualificação específica em medicina transfusional fossem autorizados a praticá-la; (3) que os currículos dos cursos de enfermagem contivessem os modernos requisitos da medicina transfusional; (4) que fossem implementados programas de avaliação e treinamentos contínuos com objetivo de melhorar a qualidade e segurança da transfusão; (5) que os conhecimentos de processos chaves fossem monitorados por procedimentos, tais como auditorias, que possibilitassem uma retro-alimentação e a implementação de ações corretivas objetivando uma melhora contínua; e (6) que manuais de orientação e protocolos sobre medicina transfusional dirigidos à enfermagem fossem desenvolvidos de acordo com as recomendações do Conselho Europeu. ${ }^{11}$

No Brasil, durante os últimos anos, muito se tem investido em tecnologia, treinamentos e programas de qualidade nos grandes centros de hemoterapia. Porém, a formação e o treinamento em serviço dos profissionais que se responsabilizam pela transfusão, fora destes centros, têm sido deixados em segundo plano. Isto compromete todo trabalho realizado antes que estes hemocomponentes cheguem ao receptor, que é o principal objetivo de todos estes esforços e investimentos.

Acreditamos na importância de mudar este quadro. É necessário rever a formação e a estrutura de treinamentos em serviço destes profissionais, entre outras medidas, para mudar esta situação.

\section{Abstract}

The risks involved in blood and blood component transfusion can be caused by inadequate procedures and mistakes or omissions by professionals responsible for transfusion. The present study aims at evaluating the level of knowledge on this issue and about the adequacy of the transfusional practices of nurses at a large university hospital in the State of São Paulo, Brazil. The study was conducted during an in-service training course on hemotherapy. A data collection instrument was applied before and after the training, when the professionals were asked about their knowledge of transfusion practices. Study participants were nurses and nursing assistants, all of whom were responsible for transfusion procedures. More than half the participants felt that they were given little information or were badly informed about transfusions. A large portion of the professionals mentioned that the signs and symptoms of transfusion reactions are not explained to patients. Many participants reported inadequate blood warming procedures. The evaluation of the knowledge showed significant defects in the education of these nursing professionals. Rev. bras. hematol. hemoter. 2007;29(2):160-167.

Key words: Knowledge; inservice training; hemotherapy; blood transfusion.

\section{Referências Bibliográficas}

1. Fitzpatrick T. Nursing management of transfusion. In: Popovisk MA, editor. Transfusion reactions. Bethesda: AABB press; 1996. p.357-83.

2. Agência Nacional de Vigilância Sanitária (BR). RDC 153 de 14/06/ 04. Brasília (DF): Diário Oficial da União; 2004.

3. Bayraktar N, Fethiye E. Blood transfusion knowledge and practice among nurses in Turkey. J Infus Nurs. 2000;23(5):310-7.

4. Conselho Federal de Enfermagem. Resolução Cofen nº. 306/2006. Rio de Janeiro, 2006.

5. Mancini ME. Performance improvement in transfusion medicine. What do nurses need and want? Arch Pathol Lab Med. 1999; 123(6):496-502.

6. Smetzer JL, Cohen MR. Lesson from Denver medication error/ criminal negligence case: look beyond blaming individuals. Hosp Pharm. 1998;33(6):640-57.

7. Saillour GF, Tricaud S, Pélissier SM, Bouchon B, Galpérine I, Fialon P, Salmi LR. Factors associated with nurses' poor knowledge and practice of transfusion safety procedures in Aquitaine, France. Int J Qual Health Care. 2002;14(1):25-32.

8. Watts DD. Correspondence analysis: a graphical technique for examining categorical data. Nursing Research. 1997;46(4):235-9.

9. Greenacre MJ. Correspondence analysis in practice. London: Academic Press; 1993.

10. SAS Institute Incorporation, 1996. SAS/STAT Software, version 6.12. Cary: SAS Institute Inc.

11. Council of Europe, 2004. Recommendation Rec (2004)18 of the Committee of Ministers. On teaching transfusion medicine to nurses. December 15, 2004.

Avaliação: Editor e dois revisores externos

Conflito de interesse: não declarado

Recebido: 10/10/2006

Aceito: 04/12/2006 